\title{
SISTEMA DE INFORMAÇÃO GEOGRÁFICA NA FORMULAÇÃO DE INDICADORES AMBIENTAIS PARA SUSTENTABILIDADE DOS RECURSOS HÍDRICOS
}

\section{LESLIE IVANA SERINO CASTRO', SERGIO CAMPOS², CÉLIA REGINA LOPES ZIMBACK ${ }^{3}$, ILZA MACHADO KAISER ${ }^{4}$}

\author{
1'Doutora em Agronomia, Irrigação e Drenagem, Faculdade de Ciências Agronômicas, Universidade Estadual \\ Paulista, Botucatu, SP, liscastro.jau@terra.com.br \\ 2 Docente do Departamento de Engenharia Rural, Faculdade de Ciências Agronômicas, Universidade Estadual \\ Paulista, Botucatu, SP, seca@ fa.unesp.br \\ ${ }^{3}$ Docente do Departamento de Recursos Naturais, Faculdade de Ciências Agronômicas, Universidade Estadual \\ Paulista, Botucatu, SP, crlzimback@ fca.unesp.br \\ ${ }^{4}$ Docente do Departamento de Engenharia Civil, Faculdade de Engenharia, Universidade Estadual Paulista, \\ Bauru, SP, ilzakaiser@feb.unesp.br
}

\section{RESUMO}

O planejamento e a gestão sustentável dos recursos hídricos requerem ações que priorizem a qualidade de vida e a recuperação e conservação dos recursos naturais. Para que isso ocorra um município deve ter instrumentos que lhe confiram o direito de exercer tais ações como, por exemplo, o Plano Diretor e os Planos Setoriais. Para a elaboração dos planos municipais, que irão nortear o desenvolvimento do município e fornecer informações para a formulação de políticas publicas é de suma importância que sejam elaborados sobre uma base de dados primários e seguros. Por essa razão, este artigo propôs a formulação de indicadores ambientais elaborados com a utilização de um Sistema de Informação Geográfica - SIG. Foi utilizado como base de dados, o diagnóstico ambiental elaborado com a utilização do gvSIG que forneceu agilidade e precisão ao processo. A área de estudo considerada foi a bacia do Rio Lençóis - SP, que possui uma boa base de dados obtidos pelo Diagnóstico Ambiental da Bacia do Rio Lençóis que foi elaborado com recursos do Fundo Estadual para Recursos Hídricos FEHIDRO, tendo como tomador o Serviço de Abastecimento de Água e Esgoto de Lençóis Paulista - SAAELP. Pelo diagnóstico foram formulados os indicadores ambientais referentes ao uso e ocupação do solo e aos recursos hídricos. Os resultados obtidos foram satisfatórios demonstrando que a metodologia utilizada é de grande importância na avaliação dos recursos hídricos, pois proporciona uma base segura para tomada de decisão buscando a adequação ambiental e o desenvolvimento sustentável. Com a utilização de indicadores ambientais podese analisar a sustentabilidade de uma área como um todo e ao mesmo tempo avaliar as partes, ou seja, em qual setor está ocorrendo problemas significativos e direcionar as ações para corrigi-los.

PALAVRAS-CHAVE: Indicadores Ambientais, Desenvolvimento Sustentável, Políticas Públicas.

\section{CASTRO, L. I. S.; CAMPOS, S.; ZIMBACK, C. R. L. ; KAISER, I. M. GEOGRAPHIC INFORMATION SYSTEM TO FORMULATE ENVIRONMENTAL INDICATORS FOR SUSTAINABILITY OF WATER RESOURCES}




\section{ABSTRACT}

Planning and sustainable management of water resources require actions that focuses on life quality, recovery and preservation of natural resources. As such, a municipality must have tools which empower the government with the right to exercise such actions, for example, the Master Plan and Sector Plans. To develop municipal plans which will guide the development of the city and provide information for establishment of public policies, it is of the utmost importance that they are designed based on primary and safe data. In view of these considerations, this study aimed at formulating environmental indicators by using a Geographic Information System - GIS. The environmental diagnosis based on the gvGIS was used as database, which made the process to be agile and accurate. The watershed of Lençóis River - SP was the study area. It has a good database from the Environmental Diagnosis of the watershed of Lençóis River, which was created through funds from the State Funds for Water Resources - FEHIDRO. The borrower was the Service of Water Supply and Sewage of Lençóis Paulista - SAAELP. Based on the diagnosis, the indicators were formulated concerning land use and occupation as well as water resources.

The results were considered satisfactory and showed that the methodology used in this study is of great importance to evaluate water resources, as it provides a reliable basis for the decision-making process seeking environmental compliance and sustainable development.

By using environmental indicators, the sustainability of an area as a whole can be analyzed, and the parts as well, i.e., it is possible to identify which sector is experiencing significant problems and take actions to solve them.

Keywords: Environmental indicators, sustainable development, public policies.

\section{INTRODUÇÃO}

\subsection{Gestão dos Recursos Hídricos}

A complexidade de se considerar um espaço geográfico amplo determina a busca de uma delimitação geográfica mais restrita que contenha a maioria das relações causa-efeito, sem se tornar de complexa operacionalidade. A adoção da bacia hidrográfica como a unidade ideal de planejamento e gestão tem sido frequente, devido ao papel integrador das águas, porém caberá ao município a compatibilização das ações dentro de seus limites, para auxiliar em sua gestão e integrar suas ações às do órgão competente pela gestão dos recursos hídricos, no caso o Estado.

As relações de conflitos entre os atores refletem a complexidade no Planejamento e Gestão dos recursos hídricos em um município e, para tanto, é de fundamental importância o estabelecimento de políticas públicas que contemplem uma visão sistêmica destes problemas, direcionando as ações políticas, econômicas, sociais e ambientais para uma visão de desenvolvimento sustentável.

Para que o município tenha um planejamento e gestão integrada de seu território é necessário que primeiramente considere a área urbana e rural para análise, pois os recursos hídricos são gerados no campo. A área urbana encontra-se consolidada e é sua expansão que deve ser considerada neste planejamento de forma integrada, para uma gestão de forma sustentável. Para isso será necessária a elaboração de diagnósticos detalhados dos aspectos 
ambientais, dos recursos hídricos, da forma de gestão utilizada pelo município utilizando para tanto de tecnologia adequada e equipe multidisciplinar.

Gestão de recursos hídricos é o "conjunto de ações que visam ao aproveitamento múltiplo e racional dos recursos hídricos, com atendimento satisfatório de todos os usos e usuários, em quantidade e padrões de qualidade. Essas ações visam, ainda, controle, conservação, proteção e recuperação desses recursos, com distribuição equitativa dos custos entre usuários e beneficiários" (Fehidro, 2000).

Ao longo do tempo vem sendo criadas e utilizadas novas tecnologias que possibilitam a mensuração e espacialização de situações reais, como é o caso dos Sistemas de Informação Geográfica, que embasam muitos outros sistemas de apoio a decisão. Essa ferramenta, no entanto, ficaria subutilizada sem o devido planejamento que vem sendo construído através de políticas públicas que contem em suas diretrizes a elaboração de planos no âmbito federal, estadual e municipal.

\subsection{Geoprocessamento}

O termo geoprocessamento denota a disciplina do conhecimento que utiliza técnicas matemáticas e computacionais para o tratamento da informação geográfica e que vem influenciando de maneira crescente as áreas de Cartografia, Análise de Recursos Naturais, Transportes, Comunicações, Energia e Planejamento Urbano e Regional. As ferramentas computacionais para geoprocessamento permitem realizar análises complexas, ao integrar dados de diversas fontes e ao criar bancos de dados georreferenciados. Em geoprocessamento, o espaço geográfico é modelado segundo duas visões complementares: os modelos de campos e objetos. O modelo de campos enxerga o espaço geográfico como uma superfície contínua, sobre a qual variam os fenômenos a serem observados segundo diferentes distribuições. $\mathrm{O}$ modelo de objetos representa o espaço geográfico como uma coleção de entidades distintas e identificáveis (Câmara et al., 2006).

Santos (2001), analisando conceitos de geoprocessamento e dos SIGs e de suas tendências à aplicação no gerenciamento de bacias hidrográficas, concluiu que as ferramentas contidas em um SIG são capazes de acelerar as análises de dados, além de serem de extrema importância no processo de diagnóstico, planejamento, projeto e gestão do espaço.

Os dados tratados em Geoprocessamento têm como principal característica a diversidade de fontes geradoras e de formatos apresentados. Entretanto, os sistemas se restringem a tratar um ou mais dos seguintes tipos de dados: temáticos, cadastrais; redes, imagens e numéricos (Câmara et al., 2006).

\subsection{SIG - Sistema de Informação Geográfica}

Um SIG pode ser definido como a ligação técnica e conceitual das ferramentas desenvolvidas pela informática para capturar, armazenar e processar dados e apresentar informações espaciais georreferenciadas. Para a formação de um banco de dados para um SIG, os mesmos são coletados através de mapas cartográficos, dados de campo como tipo de solo, precipitação, imagens de satélite, fotografias aéreas, que serão armazenados e manipulados segundo a informação que se deseja obter (Lopes \& Ferreira, 2005).

Um SIG compreende quatro elementos básicos que são: máquina, programas, dados e profissionais. O software de SIG é desenvolvido em níveis sofisticados para as mais variadas funções. Já o dado é um elemento fundamental, tendo que ser a sua coleta bastante criteriosa, e finalmente o profissional responsável pela implementação e uso do SIG que deverá ser 
adequadamente treinada e com uma visão global das questões envolvidas no projeto. É através da interação dos quatro elementos de um SIG que se pode perceber a abrangência de suas aplicações, tais como atualizações florestais; administração municipal e planejamento urbano; mapeamento de solos; monitoramento de bacias hidrográficas; gestão de redes de distribuição de água e coleta de esgoto e muitas outras. Os dados coletados são importados para o SIG para formar um modelo de dados. Um modelo de dados é um conjunto de ferramentas conceituais, utilizado para descrever como a realidade geográfica será representada no sistema. Aspecto fundamental no projeto de um SIG, o modelo descreve como a realidade geográfica será representada no computador. Nenhuma outra decisão limita tanto a abrangência e o crescimento futuro do sistema quanto a escolha do modelo de dados. $\mathrm{O}$ processo de modelagem é a forma que se dispõe para traduzir o mundo real em outros domínios (Câmara; Medeiros, 2006).

\subsection{Diagnóstico Ambiental e dos Recursos Hídricos}

Para elaboração de um diagnóstico ambiental em uma sub-bacia é necessário que seja criado um banco de dados a partir de um estudo detalhado de suas características como: solo, dados hidrometeorológicos, declividade, uso do solo, rede de drenagem, que garanta a geração de informações confiáveis e precisas. A gestão ambiental e dos recursos hídricos de uma bacia hidrográfica visa garantir rentabilidade aos agricultores, gerar empregos e arrecadação aos municípios, barrar a exclusão social e o êxodo rural, sempre preservando o meio ambiente, promovendo a recuperação das áreas degradadas, bem como a qualidade e a quantidade das águas. Para garantir o planejamento e gestão eficientes minimizando os conflitos de uso na área da bacia é necessário que tecnologias como, por exemplo, o Sistema de Informação Geográfica (SIG) seja utilizado como ferramenta de apoio para a tomada de decisão (Castro, 2008).

Os diagnósticos de sub-bacias disponíveis são elaborados por órgãos governamentais estaduais ou federais considerando bacias hidrográficas regionais e nacionais, e dessa forma, não se dispõe de informações precisas da área da sub-bacia. Muitas informações importantes são perdidas pela escala em que se realizam tais estudos.

As características físicas de uma bacia hidrográfica determinam seu comportamento, ou seja, a maior ou menor possibilidade de ocorrência de danos ambientais. Para quantificar e qualificar esse comportamento são utilizados alguns parâmetros como: o comprimento da vazão superficial, a densidade de drenagem, o índice de circularidade, o índice de forma, a declividade média da bacia e o coeficiente de rugosidade. A partir desses parâmetros, podemse estabelecer critérios para o manejo da área da sub-bacia (Rocha, 1997).

Outro aspecto relevante na análise de uma bacia hidrográfica é o regime hidrológico que ocorre em sua área, e que irá determinar o balanço hídrico da sub-bacia. A precipitação pluviométrica abastece a sub-bacia, e fenômenos básicos como evapotranspiração, evaporação, infiltração, escoamento superficial, retiram a água do sistema (Pissarra; Politano, 2003).

Martins et al. (2005) utilizaram os parâmetros fisiográficos juntamente com informações do uso da terra e ocupação humana para determinar o grau de deterioração de uma sub-bacia e propor um zoneamento ambiental. Os resultados obtidos permitiram avaliar a deterioração ambiental da sub-bacia e abrir possibilidades para elaborar prognósticos para um maior equilíbrio no futuro manejo da sub-bacia e de sua preservação tendo, como pressuposto, o equilíbrio possível entre o desenvolvimento com a preservação ambiental. 
O uso de um recurso ambiental raramente ocorre de forma isolada. A gestão dos recursos hídricos tem repercussões no uso do solo, e vice-versa. Desta forma, as águas não podem ser geridas de forma isolada, mas sua gestão deve ser articulada no quadro da gestão de todos os recursos ambientais, que deve ser realizada pelo ordenamento territorial. Alguns recursos ambientais, como o solo, podem ser geridos com razoável eficiência através da admissão da propriedade privada. Isto decorre de que a maioria das consequências de uma boa ou má gestão como é espacialmente limitado atingindo, via de regra, a própria área onde se verifica, ou seja, a propriedade agrícola. No caso dos recursos hídricos isto geralmente não ocorre pelo fato de ser um recurso fluido e móvel. A poluição de um rio pode ser causada a montante de um rio e as consequências são sofridas nas propriedades a jusante deste mesmo rio (Lanna, 2004).

Barbosa et al. (2009) apresentaram uma nova visão de gerenciamento de recursos hídricos, transformando cada município em um Sistema de Gerenciamento Ambiental (SGA) em Área de Preservação Ambiental Municipal (APAM) estabelecida em cada município em todo o seu território municipal, onde cada gestão hídrica é uma fórmula integrada de gerenciamento, onde os seus integrantes são, invariavelmente, os próprios conhecedores ou moradores no próprio espaço físico-geográfico.

Ao analisar a micro bacia hidrográfica do Ribeirão Lindóia, Zona Norte de LondrinaPR, Araújo \& Pinese (2012) mostraram as diferentes abordagens e concepções que são trabalhadas as micro bacias como unidades de recorte espacial para o planejamento, manejo e gestão ambiental e formularam uma Matriz de Impacto Ambiental para servir de instrumento ao planejamento e gestão da área.

Para implantar um Sistema de Gestão Ambiental, é necessário diagnosticar os aspectos ambientais relevantes e tais diagnósticos devem ser feitos de forma sistemática, coordenada e integrada, buscando identificar as possíveis fontes de alteração ambiental. Fazer o controle periódico dessas fontes é importante para reduzir sua ação e prevenir acidentes, sempre segundo a legislação vigente, evitando então passivos ambientais e contribuindo para a qualidade do meio ambiente, bem como para uma melhor administração geral (Porto; Teixeira, 2002).

\subsection{Indicadores de sustentabilidade}

O projeto GEO Cidades foi criado pelo PNUMA - Programa das Nações Unidas para o Meio Ambiente, com o objetivo fundamental de definir uma padronização metodológica para o desenvolvimento de avaliações mais precisas sobre o estado do meio ambiente em áreas urbanizadas, a partir de determinantes específicos, com a formulação de indicadores de sustentabilidade (PNUMA, 2012).

Pompermayer (2003), em seu estudo, afirmou que existem várias técnicas e instrumentos de auxílio à tomada de decisão em gestão de recursos hídricos e propôs, como instrumento de auxílio à decisão, o uso de indicadores de sustentabilidade ambiental associado a técnicas de análise multicritério. Seu principal objetivo foi formular um procedimento multicritério como instrumento de auxílio à tomada de decisão na gestão de recursos hídricos e a simulação do seu uso em uma bacia hidrográfica. Utilizou como base um diagnóstico da área de estudo e em uma estrutura conceitual de indicadores denominada Pressão-Estado-Resposta e foram selecionados vinte indicadores de sustentabilidade. Foi realizada uma classificação das sub-bacias que integram a área de estudo por ordem de preferência e/ou necessidade em relação a categorias de intervenção pré-estabelecidas. A 
proposta de indicadores selecionada e o método multicritério utilizado (ELECTRE III) foram bastante adequados ao caso estudado.

Coelho (2008) elaborou o IGSA - Indicador Global de Avaliação da Sustentabilidade Ambiental de Empreendimentos com a intenção de avaliar a sustentabilidade e adequação de novos empreendimentos imobiliários em Portugal, preocupado com o desenvolvimento urbano desordenado que é considerado um problema grave para a sustentabilidade ambiental global no país. Este índice utiliza a metodologia FPEIR - Força Motriz, Pressão, Estado, Impacto, Resposta e gera um índice global a partir dos indicadores considerados, possibilitando desta forma uma avaliação criteriosa do empreendimento, adequada às exigências legais tornando-o assim sustentável e gerando uma ferramenta eficiente para que os órgãos ambientais possam ter segurança na hora do licenciamento.

\subsection{Sistemas de Indicadores}

Alguns países envolvidos com produção estatística, em particular a Europa, iniciaram o avanço na construção de indicadores desde os anos 70 tentando construir um subsistema específico sobre o meio ambiente. Após uma série de reuniões, nas décadas de 70 e 80 , foram estabelecidas diretrizes gerais para as estatísticas, do meio ambiente de interesse dos países europeus, voltando-se para o desenvolvimento de indicadores ambientais. O Canadá por sua vez, um dos países de vanguarda na área das estatísticas ambientais, criou e divulgou, sistematicamente, um conjunto de indicadores ambientais. $\mathrm{O}$ envolvimento do Escritório de Estatística das Nações Unidas (EENU) na área das estatísticas ambientais teve início em 1979 por recomendação da Comunicação de Estatística, da ONU, que em sua primeira reunião em 1984 elaborou o "Esquema para o Desenvolvimento de Estatísticas Ambientais 12" (EDEA), após amplo levantamento das principais preocupações dos países interessados. Posteriormente, considerando que as estatísticas ambientais devem cobrir tanto o meio ambiente natural como o construído pelo homem, o EENU, em 1988, produziu dois relatórios técnicos, com base no EDEA: "Conceitos e Métodos de Estatísticas do Meio Ambiente Natural"13 (EAN) e "Estatísticas de Assentamentos Humanos"14(EAH) e foi instituído o Grupo Intergovernamental para o Avanço das Estatísticas Ambientais (Coelho, 2008).

Os indicadores têm sido utilizados por diversos organismos e instituições voltados para causas ambientais e com os mais diversos objetivos, entre eles o mapeamento, a avaliação ambiental, o monitoramento do estado do meio ambiente, com relação ao desenvolvimento sustentável. Os indicadores permitem a quantificação e simplificação de fenômenos facilitando assim a compreensão de realidades complexas.

A OCDE - Organização para a Cooperação e Desenvolvimento Econômico tem a definição de indicador como sendo um parâmetro ou valor calculado a partir dos parâmetros, fornecendo ou descrevendo as indicações do estado de um fenômeno, bem como do meio ambiente ou de uma zona geográfica, de uma amplitude superior às informações diretamente ligadas ao valor de um parâmetro. (Toledo, 2005).

Para que seja possível desenvolver um município sustentável com políticas públicas voltadas para os aspectos de preservação ambiental, social e econômica são necessárias informações geradas a partir de indicadores que reflitam as condições locais, transformando dimensões qualitativas em quantitativas facilitando a compreensão por parte da sociedade envolvida na avaliação. A gestão desta política pública por programas inseridos nos planos de governos (federal, estadual e municipal) deve buscar uma sintonia que pode resultar em maior eficácia e efetividade dos objetivos e metas dos programas. (Silva \& Lima, 2010). 
Sobre as metodologias aplicadas para elaboração de modelos de indicadores Coelho (2008) fez alguns comentários a respeito:

1. Não existe o modelo de um sistema, existem sim modelos que expressam diferentes pontos de vista, ideias e objetivos e, desta forma, podem e devem ser aplicados consoante o estudo, caso a caso;

2. Todo o modelo é uma simplificação da realidade e, portanto, requer a seleção de alguns fatores que o modelador julga relevante para a compreensão do sistema;

3. Todo o modelo é imperfeito e pode ser melhorado, pois o trabalho de modelação é dinâmico e nunca está completo;

4. Um bom modelo é aquele que atinge, junto aos seus utilizadores, os objetivos definidos pelo modelador. Definir de uma maneira clara os objetivos a serem atingidos e os usos, podem determinar o sucesso ou o fracasso de um modelo.

Este trabalho teve o objetivo de formular indicadores a partir do uso de um SIG, gerando uma ferramenta de apoio à decisão, que possibilitará ao município avaliar sua sustentabilidade para o planejamento e a gestão de seu território.

\section{MATERIAL E MÉTODOS}

\section{1 Área de Estudo}

O Estado de São Paulo está dividido em 22 Unidades de Gestão de Recursos Hídricos - UGRHI que correspondem às divisões de bacias hidrográficas. A bacia Tietê-Jacaré, que é a UGRHI 13, está localizada na porção centro oeste do Estado de São Paulo e abrange 34 municípios. A bacia do Rio Lençóis faz parte da sub-bacia 4 na divisão da bacia Tietê-Jacaré e sua área está compreendida entre as coordenadas UTM 22k 699.037; 7.477.195 e 753.726; 7.515.834, que formam seu retângulo envolvente, com $942,532 \mathrm{~km}^{2}$. É uma bacia regional, pois sua rede de drenagem abrange os municípios de Agudos, onde nasce e se estende pelos municípios de Borebi, Lençóis Paulista, Areiópolis, Macatuba, São Manoel e Igaraçu do Tietê, onde desagua no Rio Tietê.

A área de estudo compreende a bacia do Rio Lençóis e a escolha deve-se ao fato da existência de uma base de dados construída através da elaboração do "Diagnóstico Ambiental na Bacia do Rio Lençóis", com a utilização de um Sistema de Informação Geográfica - SIG. O SIG utilizado foi o gvSIG que é um projeto de código aberto desenvolvido para a gestão integral da informação geográfica. Tem sua origem no contexto de migração para software livre de todos os sistemas informáticos do Departamento de Infraestrutura e Transportes da Generalitat Valenciana - Espanha. Este diagnóstico foi realizado com recursos do FEHIDRO - Fundo Estadual para os Recursos Hídricos, tendo como tomador o Serviço de Abastecimento de Água e Esgoto de Lençóis Paulista, que possui parte de seu abastecimento de água pela captação superficial no Rio Lençóis.

A sub-bacia do Rio Lençóis tem início no município de Agudos com o Córrego Taperão e somente após receber as águas do Córrego do Serrinha, passa a ser denominado Rio Lençóis, que dá o nome à bacia. Possui diversos afluentes de sua nascente até sua foz e muitos deles atravessam áreas urbanas dos municípios. O Rio Lençóis atravessa a área urbana do município de Lençóis Paulista e serve de manancial de abastecimento. São seus afluentes na margem esquerda: Córrego dos Cochos, Córrego Monjolinho, Córrego do Bobirão, Córrego Corvo Branco, Córrego Cateto, Córrego Violeta (Córrego do Boa Vista), Córrego da Iara e Córrego Santana ou Jurema. São seus afluentes na margem direita: Córrego das Antas, 
Ribeirão São Mateus, Córrego da Estiva, Ribeirão Faxinal, Córrego do Marimbondo, Ribeirão da Prata, Córrego do Cachoeirinha, Ribeirão da Barra, Ribeirão da Fartura (Córrego do Corguinho), Córrego da Areia Branca, Córrego do Coqueiro, Córrego da Grama e Ribeirão Paraíso.

\subsection{Metodologia}

O projeto foi iniciado com a utilização da base de dados citada, foi elaborada a partir do tratamento e importação para o SIG, de mapas cartográficos e imagens. Foram importadas para o gvSIG as cartas planialtimétricas do Instituto Geográfico e Cartográfico - IGC, onde foi realizada a correção geométrica e a vetorização das feições presentes em cada carta (rede de drenagem e curvas em nível). Esse procedimento possibilitou a realização do traçado do divisor de águas da bacia e a elaboração do MNE - Modelo Numérico de Elevação, a partir do qual foram gerados os mapas de declividade e hipsométrico, que formaram a base para a geração do mapa de capacidade de uso do solo. Também foi importado para o SIG o mapa de solos do Instituo Agronômico de Campinas - IAC, da região da bacia do Rio Lençóis. As imagens ALOS foram trabalhadas para a montagem do mosaico da bacia, para que fosse realizada a atualização de toda rede de drenagem, bem como o mapeamento em tela do uso e ocupação na área da bacia. A atualização da rede de drenagem foi executada sobrepondo-se a vetorização dos rios realizada pelas cartas do IGC - 1980, sobre as imagens de 2010. Os usos foram definidos da seguinte forma: cana-de-açúcar, pastagem, mata ciliar, cultura perene, cultura anual, área urbana consolidada, edificações rurais, vegetação nativa e silvicultura, sendo delimitação dos usos realizada utilizando a metodologia de verdade terrestre em tela.

Foram geradas as Áreas de Preservação Permanente - APP pela rede de drenagem atualizada, nos cursos de água, bem como nas nascentes que devem apresentar APP diferenciada, segundo o Código Florestal Lei $n^{\circ}$ 12.727/2012. Para auxiliar na formação do diagnóstico ambiental foi gerado pelo SIG um mapa de capacidade do uso da terra tendo como base o sistema de classificação de terras em capacidade de uso desenvolvido por Lepsch et al. (1991), para atender planejamentos de práticas de conservação do solo. Foram consideradas as capacidades de uso do Grupo A, Classes I, II, III e IV que se referem ao cruzamento das informações de solo e declividade. O mapa de conflitos de usos foi gerado com o cruzamento do mapa de uso no local e o mapa de capacidade de uso. Também foi gerado um mapa específico de conflito em APP. A disponibilidade de água foi verificada pela $\mathrm{Q}_{7,10}$, que representa a vazão mínima anual de 7 dias consecutivos com 10 anos de período de retorno, da vazão regionalizada do DAEE - Departamento de Água e Energia Elétrica do Estado de São Paulo. Foram realizadas medições diretas de vazão nos corpos de água da bacia. A medição teve como objetivo a verificação da variação das vazões nos períodos de cheia e estiagem e foi agregado aos indicadores. As características da bacia que foram estimadas nesse trabalho são: área de drenagem, forma da bacia determinada pelos: coeficientes de compacidade e de forma, densidade de drenagem, declividade média e sinuosidade do curso de água e perfil longitudinal do rio. Esses parâmetros formaram a base de dados para os indicadores de uso e ocupação de forma indireta.

Desta forma, a partir do diagnóstico ambiental realizado com técnicas de geoprocessamento, que garantiu a quantificação e espacialização da área, foram formulados os indicadores ambientais na bacia do Rio Lençóis.

Tanto o diagnóstico como os indicadores escolhidos e formulados neste trabalho servirão para os municípios que fazem parte da bacia estudada embasar suas decisões e planejamentos. 
A seleção dos indicadores consistiu naqueles mais relevantes para uma administração municipal, que tem sob sua responsabilidade o aumento populacional, que demanda por água potável, afastamento e tratamento dos efluentes gerados, disposição adequada dos resíduos gerados, questões referentes à drenagem urbana. Tudo isso sem deixar o município perder a qualidade ambiental, devendo para tanto, atender à legislação ambiental, dos recursos hídricos e de saneamento. Os indicadores foram selecionados considerando-se o uso e ocupação do solo e a água, pois estas variáveis se relacionam e reagem conforme as modificações impostas pela ação antrópica.

Para a formulação dos indicadores relativos ao uso e ocupação do solo foram feitas as perguntas:

1. Como está o uso do solo no município? Está adequado à capacidade de uso?

2. Quanto os usos estão provocando a supressão de cobertura vegetal;

3. Como estão as áreas de Preservação Permanente?

Para compor os indicadores referentes à água foram feitas as perguntas:

1. Qual a disponibilidade de água - superficial e subterrânea atualmente explorada?

2. Qual a condição ambiental dos mananciais de água superficial?

3. Os mananciais suportam o aumento de demanda?

4. Como está o Sistema de Abastecimento de Água - SAA com relação à: tratamento adequado garantindo a qualidade, pontos de controle de qualidade da água, controle de perdas no sistema, capacidade de tratamento?

5. Os efluentes recebem tratamento antes de serem devolvidos aos corpos receptores?

6. A eficiência desse tratamento está adequada?

7. A montante da captação existe lançamentos que comprometem a qualidade da água? Para formulação dos indicadores foi utilizada a metodologia descrita por Coelho ( 2008) que utilizou um indicador/índice global para a avaliação da sustentabilidade de novos empreendimentos. Neste artigo se adaptou esta metodologia para a avaliação da sustentabilidade dos recursos hídricos na bacia do Rio Lençóis. Desta forma o índice total é formado pela soma dos valores parciais de cada ação multiplicada pelos pesos definidos conforme a expressão 1 .

$\mathrm{V}(\mathrm{ta})=\mathrm{v} 1(\mathrm{a}) \cdot \mathrm{w} 1+\mathrm{v} 2(\mathrm{a}) \cdot \mathrm{w} 2+\mathrm{v} 3(\mathrm{a}) \cdot \mathrm{w} 3+\ldots+\mathrm{vn}(\mathrm{a}) \cdot \mathrm{wn}$

Onde:

V(ta) - Valor Total da ação a;

v1(a), v2(a), ... vn(a) - Valor parcial da ação "a" nos critérios $1,2, \ldots$, n;

w1, w2, .., wn - Pesos ou Taxas de Substituição dos critérios 1, 2, .., n.

O peso (taxa de substituição) de um critério é a sua importância no modelo, ou de forma mais simples, a sua taxa de substituição no modelo. Neste trabalho, foram atribuídos pesos aos indicadores descritos a partir de pesquisas bibliográficas que embasaram os indicadores utilizados pela Secretaria Estadual de Saneamento e Recursos Hídricos do Estado de São Paulo para elaboração dos Relatórios de Situação das Bacias Hidrográficas do estado e opiniões de especialistas que descrevem graus de importância à cada indicador avaliado. Para cada indicador foi aplicada a tabela de valores equivalentes que seguiu a definição da Tabela 1. 
Tabela 1. Critérios definidos para atribuição de valores aos indicadores ambientais

\begin{tabular}{ccc}
\hline SITUAÇÃO & AÇÃO & VALORES \\
\hline Ótima & Totalmente adequada & 100 \\
Bom & Adequada com alguma restrição & 80 \\
Regular & Consolidada buscando adequações & 60 \\
Ruim & Inadequada passível de recuperação & 30 \\
Péssima & Inadequada sem possibilidade de recuperação & 0 \\
\hline
\end{tabular}

Para cada indicador foi gerado um valor ou faixa de valor, que corresponde ao valor da ação equivalente. Para cada ação foi definido um valor que corresponde aos critérios da situação correspondente. Desta forma para o valor de cada ação encontrado pelos parâmetros analisados e, enquadrando-os aos valores referidos, pode ser encontrado o valor do indicador. Esses valores serão multiplicados pelos pesos atribuídos, (expressão 1) e somados para que se chegue ao valor total de avaliação, tendo então os valores parciais que permitirão saber quais áreas são prioritárias para intervenção e como está o município frente às questões ambientais e dos recursos hídricos.

\section{RESULTADOS E DISCUSSÕES}

Serão apresentados a seguir os resultados obtidos pelo diagnóstico ambiental elaborado a partir da tecnologia de geoprocessamento que garantiu uma maior agilidade e precisão na aquisição e geração das informações e possibilitou a atribuição de valores, diretos e indiretos aos indicadores.

Pela atualização da rede de drenagem pode-se constatar a perda de $17 \%$ do comprimento total da rede de drenagem, que correspondem a 174,821 km, conforme Tabela 2.

Tabela 2. Atualização do comprimento da rede de drenagem na bacia do Rio Lençóis - SP.

Comprimento total dos canais IGC 1980 (Lt)

Comprimento total dos canais atualizada - 2010 (Lt_at)

Perda de comprimento dos canais

Perda de comprimento dos canais em porcentagem
$1.028,479 \mathrm{~km}$

$853,658 \mathrm{~km}$

$174,821 \mathrm{~km}$

$17 \%$

A Figura 1 demonstra essa perda no comprimento total dos canais. 
Figura 1. Atualização da Rede de Drenagem da Bacia do Rio Lençóis - SP.

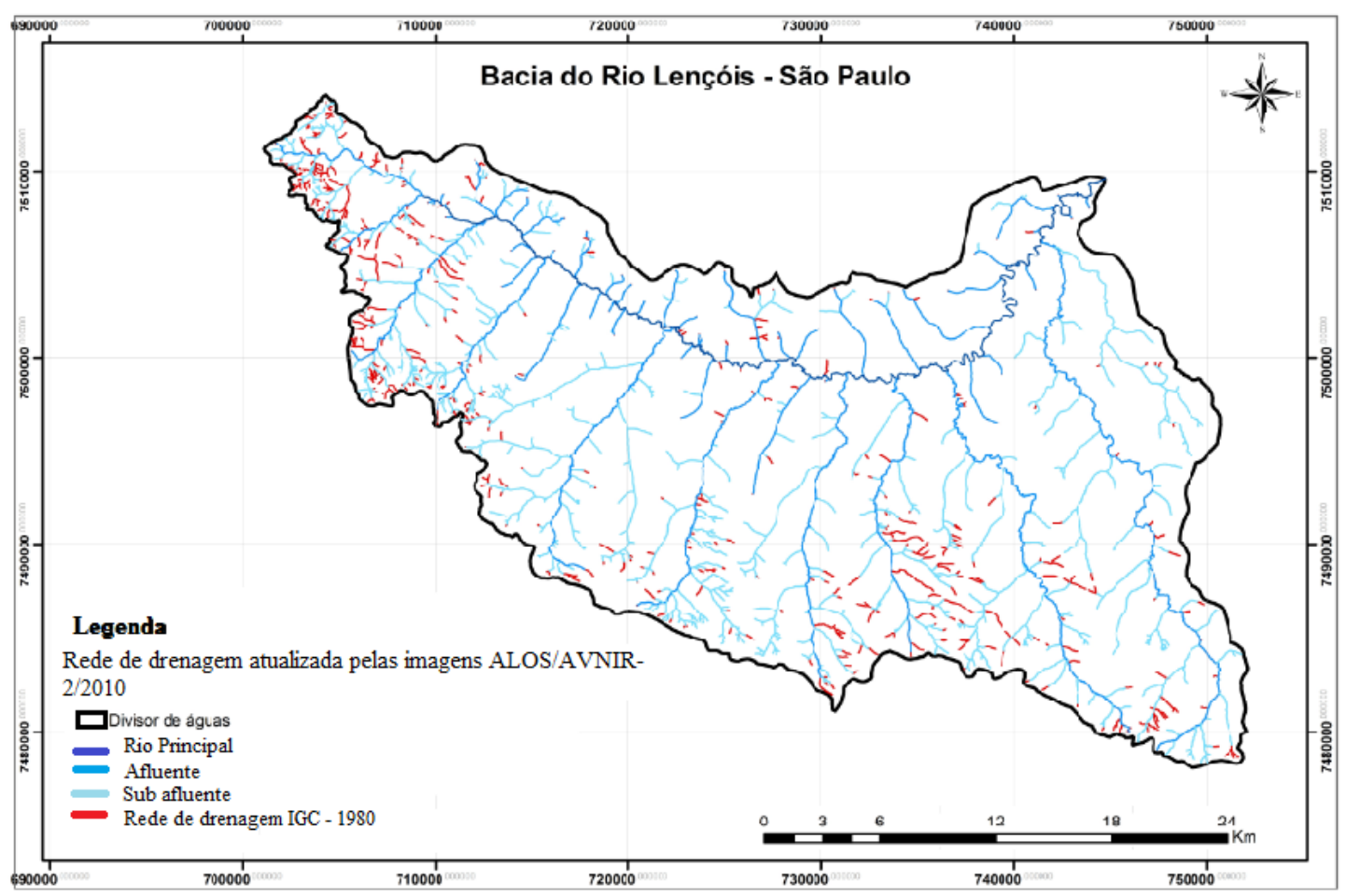

A Figura 2 e Tabela 3 contém o resultado do mapeamento dos usos encontrados na área da bacia do Rio Lençóis.

Figura 2. Mapa de uso e ocupação da área da bacia do Rio Lençóis - SP.

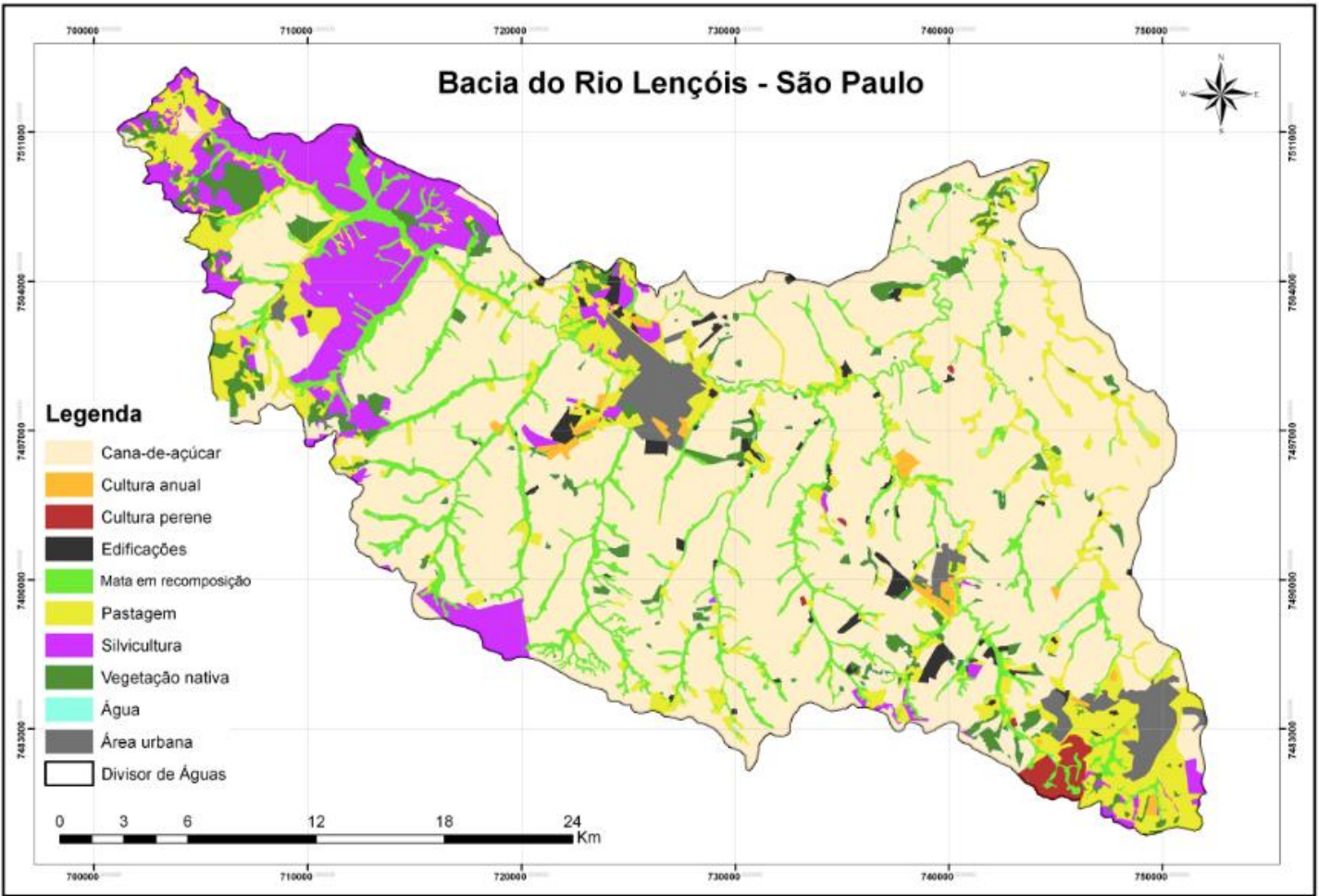


Tabela 3. Quantificação dos usos encontrados na área da bacia do Rio Lençóis - SP

\begin{tabular}{lcc}
\hline USO & ÁREA $-\mathbf{~ k m}^{\mathbf{2}}$ & \% \\
\hline Área Urbana Consolidada & 27,216 & 2,888 \\
Edificações Rurais & 10,659 & 1,131 \\
Silvicultura & 81,157 & 8,611 \\
Cana-de-Açúcar & 609,661 & 64,683 \\
Vegetação Nativa & 36,839 & 3,909 \\
Mata em Recomposição & 73,380 & 7,785 \\
Cultura Anual & 6,431 & 0,682 \\
Cultura Perene & 5,095 & 0,541 \\
Pastagem & 90,903 & 9,645 \\
Agua & 1,190 & 0,126 \\
\hline TOTAL & $\mathbf{9 4 2 , 5 3 2}$ & $\mathbf{1 0 0}$ \\
\hline
\end{tabular}

Pode-se constatar a grande predominância da cultura da cana-de-açúcar na área da bacia $(64,68 \%)$ e apenas $10 \%$ da área com mata nativa e em recomposição. A Tabela 4 demonstra os usos que ocorrem especificamente nas áreas que correspondem à APP das nascentes.

Tabela 4. Usos encontrados nas nascentes da bacia do Rio Lençóis - SP.

\begin{tabular}{lc}
\hline USOS DO SOLO & ÁREA $-\mathbf{k m}^{\mathbf{2}}$ \\
\hline Área Urbana de Lençóis Paulista & 0,02 \\
Área Urbana de São Manoel & 0,04 \\
Silvicultura & 0,45 \\
Cana-de-Açúcar & 1,28 \\
Vegetação Nativa & 0,48 \\
Mata em recomposição & 1,30 \\
Cultura Anual & 0,01 \\
Cultura Perene & 0,01 \\
Edificações & 0,01 \\
Pastagem & 0,84 \\
\hline TOTAL & $\mathbf{4 , 4 4}$ \\
\hline
\end{tabular}

Dos 4,44 km² de APP conjuntamente com as nascentes, apenas $1,78 \mathrm{~km}^{2}$ apresentam vegetação adequada.

O mapa que compõe a Figura 3 foi gerado para verificação de áreas de conflitos de usos na bacia do Rio Lençóis. A Tabela 5 contém a quantificação das áreas adequadas e não adequadas. 
Figura 3. Conflito de usos em função das classes existentes na área da bacia do Rio Lençóis SP.

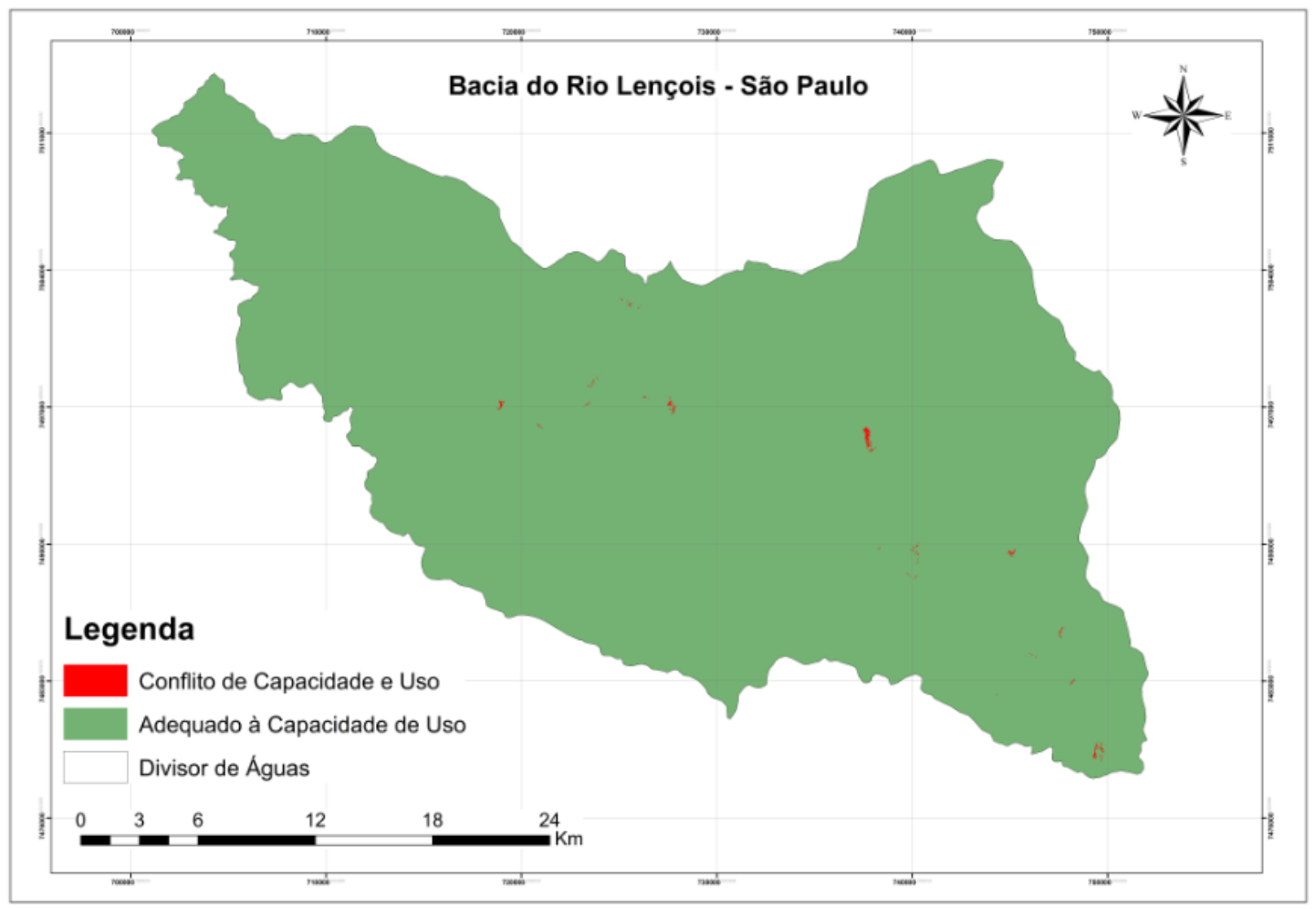

Tabela 5. Conflito de usos em função das classes existentes na área da bacia do Rio LençóisSP

\begin{tabular}{lcc}
\hline USO & ÁREA $-\mathbf{k m}^{\mathbf{2}}$ & $\mathbf{\%}$ \\
\hline Conflito de Capacidade de uso & 6,148 & 0,65 \\
Adequado à Capacidade de uso & 936,384 & 99,35 \\
\hline TOTAL & $\mathbf{9 4 2 , 5 3 2}$ & $\mathbf{1 0 0}$ \\
\hline
\end{tabular}

Observa-se que a maior parte da área da bacia do Rio Lençóis $\left(936,384 \mathrm{~km}^{2}\right)$, tem seu uso adequado pela capacidade e apenas $6,148 \mathrm{~km}^{2}$ apresenta conflito, pois existe o cultivo de cultura anual em área definida como classe IV de capacidade de uso.

A Figura 4 e Tabela 6 estão demonstrando quanto da área de preservação permanente na área da bacia encontra-se degradada.

Tabela 6. Conflito de uso em APP pela falta de mata ciliar na bacia do Rio Lençóis - SP

\begin{tabular}{ccc}
\hline USO & ÁREA $-\mathbf{k m}^{\mathbf{2}}$ & $\mathbf{\%}$ \\
\hline Adequado & 37,074 & 65,67 \\
Degradado & 19,391 & 34,33 \\
\hline TOTAL & $\mathbf{5 6 , 4 6 6}$ & $\mathbf{1 0 0}$ \\
\hline
\end{tabular}

Pode-se afirmar que dois terços da APP encontram-se em situação de adequação $(65,67 \%)$ e um terço $(34,34 \%)$ encontra-se vegetada inadequadamente.

As condições de uso e ocupação do solo na bacia de drenagem a montante da cidade de Lençóis Paulista geram impactos negativos ao balanço hídrico, potencializando a 
ocorrência de extremos no regime de escoamento e erosão com aumento da carga de sedimentos.

Figura 4. Conflito de uso em APP pela falta de mata ciliar na bacia do Rio Lençóis - SP.

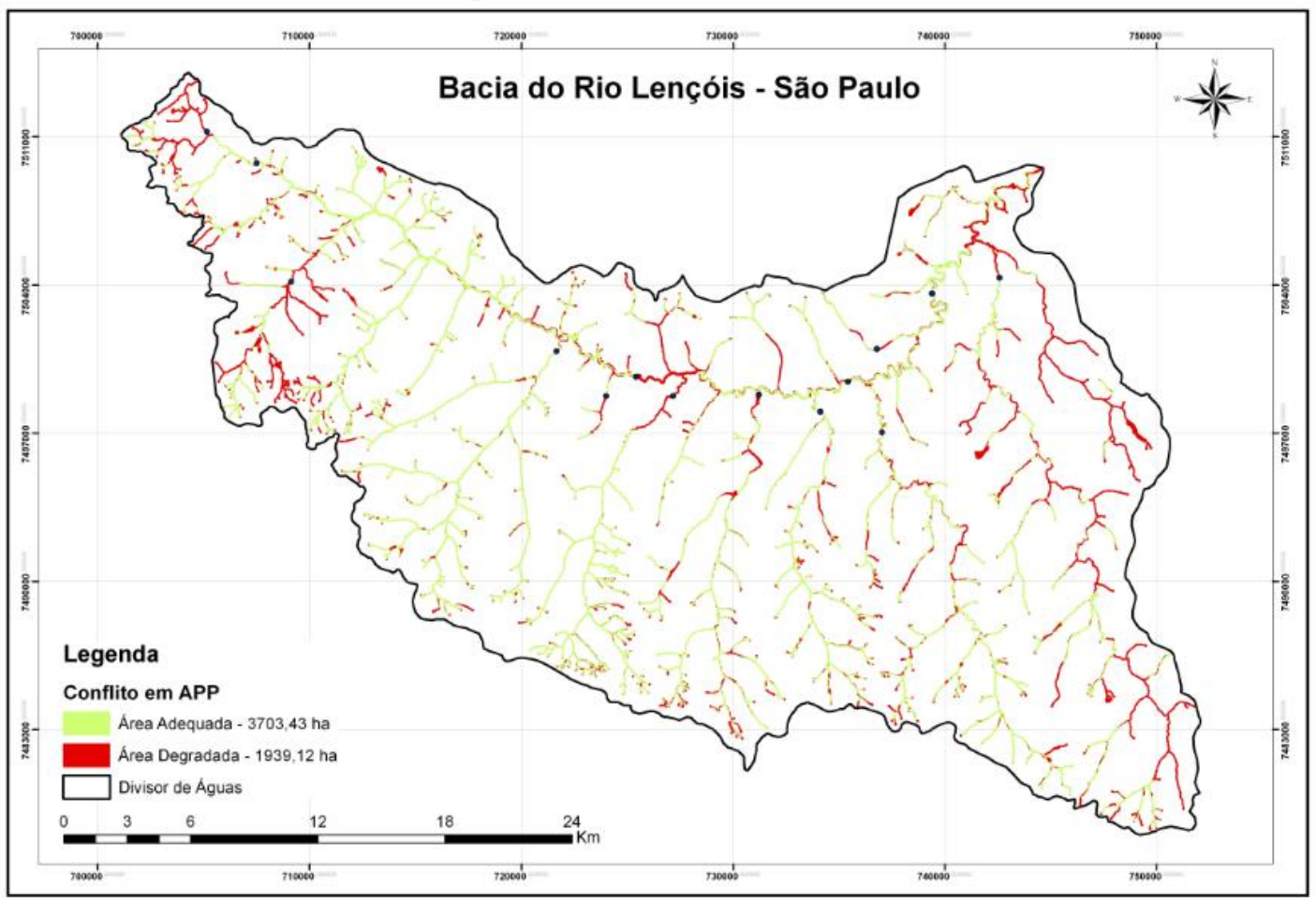

Os indicadores formulados a partir das informações geradas pelo diagnóstico ambiental elaborado com a utilização do gvSIG foram:

a) Índice de Cobertura Vegetal (ICV);

b) Índice de Quantidade de Água (IQtA);

c) Índice de qualidade da Água (IQlA);

d) Índice de Interferência no Uso do Solo (IIUS) e

e) Índice de Interferência no Uso dos Recursos Hídricos (IIURH).

Para cada um foi definido um quadro de valores atribuídos para aplicação dos valores correspondentes encontrados na área de estudo.

a) ICV

Este indicador considerou o uso e ocupação do solo e as APP. E a avaliação para a pontuação foi elaborado com as informações extraídas do diagnóstico ambiental da bacia do Rio Lençóis.

A Tabela 7 demonstra os valores correspondentes para cada situação considerada. 
Tabela 7. Valores correspondentes para o Índice de Cobertura Vegetal para formulação do Indicador de Estado Ambiental.

\begin{tabular}{lcc}
\hline Situação & \multicolumn{1}{c}{ Adequação do uso do solo } & Valores \\
\hline Ótima & Uso adequado com ações de recuperação > 60\% de APP & 100 \\
Bom & Uso adequado com ações de recuperação de 30- 60\% de APP & 80 \\
Regular & Uso adequado com ações de recuperação de 0 - 30\% de APP & 60 \\
Ruim & Uso adequado sem ações de recuperação em APP & 30 \\
Péssima & Uso inadequado sem ações de recuperação em APP & 0 \\
\hline
\end{tabular}

Para enquadramento a este índice foram utilizadas as informações contidas nos mapas de conflitos de uso e conflitos em APP, além da quantificação de nascentes com recomposição florestal. A pontuação correspondente fica em 60.

\section{b) IQtA}

Este índice pontua de acordo com a disponibilidade de água bruta, ou seja, a disponibilidade hídrica superficial relacionada à situação dos corpos de água. Foi verificada a situação referente ao assoreamento dos corpos de água, pela atualização do comprimento da rede de drenagem na bacia e situação das nascentes e APP. Foram atribuídas faixas de "encolhimento" dos corpos de água comparando-se estudos realizados em outras bacias.

A Tabela 8 demonstra a pontuação das situações correspondentes.

Tabela 8. Valores correspondentes para o Índice de Quantidade de Água para formulação do Indicador.

\begin{tabular}{|c|c|c|}
\hline Situação & Degradação X Recuperação & Valores \\
\hline Ótima & $0-5 \%<$ com recuperação > 60\% das APP em nascentes e margens & 100 \\
\hline Bom & $\begin{array}{c}5-10 \%<\text { com recuperação de } 30-60 \% \text { das APP em nascentes e } \\
\text { margens }\end{array}$ & 80 \\
\hline Regular & $\begin{array}{c}10-20 \%<\text { com recuperação de } 0-30 \% \text { das APP em nascentes e } \\
\text { margens }\end{array}$ & 60 \\
\hline Ruim & $\begin{array}{l}>20 \% \text { com recuperação }<30 \% \text { das APP em nascentes e } \\
\text { margens }\end{array}$ & 30 \\
\hline Péssima & $>20 \%$ sem recuperação das APP em nascentes e margens & 0 \\
\hline
\end{tabular}

Para este indicador a área obteve pontuação de 60.

\section{c) IQIA}

Este índice mede a qualidade da água bruta $(\mathrm{AB})$ e água tratada $(\mathrm{AT})$ pelo atendimento dos padrões de qualidade pela legislação vigente. Através deste índice pode ser verificado se ocorrem despejos de efluentes nos córregos e a adequação do sistema de tratamento ao tipo de água captada. Atualmente os serviços de abastecimento de água devem obedecer à Portaria 2914/2011 do Ministério da Saúde, sendo que os municípios tem até 4 anos para se adequar a ela. avaliação.

A Tabela 9 demonstra a pontuação atribuída a cada situação considerada para 
Tabela 9. Valores correspondentes para o Índice de Qualidade da Água para formulação do Indicador Ambiental.

\begin{tabular}{lcc}
\hline Situação & \% de atendimento aos padrões exigidos para AB e AT & Valores \\
\hline Ótima & $100 \%$ & 100 \\
Bom & $80-99 \%$ & 80 \\
Regular & $60-79 \%$ & 60 \\
Ruim & $50-59 \%$ & 30 \\
Péssima & $<50 \%$ & 0 \\
\hline
\end{tabular}

Para o índice de qualidade da água bruta e tratada, a área obteve pontuação 80 pela qualidade da água bruta que denota necessidade de recuperação ambiental.

\section{d) IIUS}

Este índice considerou os impactos causados pela interferência no uso do solo de forma desordenada que causam erosão, assoreamento dos corpos de água, remoção de cobertura vegetal com conflitos dos usos do solo e ocorrência de enchentes nas áreas urbanizadas. A situação ótima prevê que a área rural está adequada conforme a capacidade de uso do solo e com ações ambientalmente adequadas de manejo e a área urbana com o atendimento das restrições do PD visando minimizar os impactos ambientais causados pela urbanização. A Tabela 10 demonstra os valores correspondentes à cada situação.

Tabela 10. Valores correspondentes para o Índice de Interferência no Uso do Solo.

\begin{tabular}{lcc}
\hline Situação & Adequação do uso do solo urbano e rural & Valores \\
\hline Ótima & $80-100 \%$ adequado & 100 \\
Bom & $60-80 \%$ adequado & 80 \\
Regular & $40-60 \%$ adequado & 60 \\
Ruim & $20-40 \%$ adequado & 30 \\
Péssima & $<20 \%$ adequado & 0 \\
\hline
\end{tabular}

Nesta pontuação a área recebeu pontuação 80 , pois a área rural está em sua maioria adequada ao uso, porém a área urbana merece mais atenção com relação a ações de drenagem sustentável.

\section{e) IIURH}

Para este índice foram considerados os impactos sofridos nos recursos hídricos pela expansão urbana. Os impactos no uso do solo interferem nos recursos hídricos da mesma forma que este último interfere no uso do solo. Sendo assim para este índice a situação ótima será considerada para a porcentagem de APP preservada, que também interfere no balanço hídrico que define o regime de chuvas e de clima. A Tabela 11 demonstra os valores correspondentes à cada situação.

Tabela 11. Valores correspondentes para o Índice de Interferência no Uso dos Recursos Hídricos.

\begin{tabular}{lcc}
\hline \multicolumn{1}{c}{ Situação } & \% APP florestada & Valores \\
\hline Ótima & $80-100 \%$ & 100 \\
Bom & $60-80 \%$ & 80 \\
Regular & $40-60 \%$ & 60 \\
Ruim & $20-40 \%$ & 30 \\
Péssima & $<20 \%$ & 0 \\
\hline
\end{tabular}



critério ruim.

Neste índice foi obtida a pontuação 30, pois apresenta uma área correspondente ao

Os pesos correspondentes a cada indicador, bem como o resultado estão na Tabela 12.

Tabela 12. Resumo dos valores e pesos para cada índice

\begin{tabular}{cccc}
\hline INDICADOR & VALOR & PESO & RESULTADO \\
\hline ICV & 60 & 0,40 & \\
IQtA & 60 & 0,30 & 66 \\
IQ1A & 80 & 0,30 & \\
\hline IIUS & 80 & 0,50 & \multirow{2}{*}{55} \\
IIURH & 30 & 0,50 & \\
\hline
\end{tabular}

Também foram atribuídos os pesos referentes a cada grupo de indicadores, quais sejam, os de uso e ocupação do solo e os referentes aos recursos hídricos. Ambos receberam peso 0,50 , pois as ações antrópicas interferem e refletem igualmente em ambos.

A Tabela 13 representa os valores de cada indicador após a aplicação da expressão (1), multiplicado pelo respectivo peso.

Tabela 13. Valores para cada indicador

\begin{tabular}{ccc}
\hline INDICADOR & VALOR X PESO & RESULTADO \\
\hline Uso e ocupação do solo & $66 \times 0,50$ & 33,00 \\
Recursos hídricos & $55 \times 0,50$ & 27,50 \\
\hline \multicolumn{2}{c}{ TOTAL } & $\mathbf{6 0 , 5 0}$
\end{tabular}

A Tabela 12 expressa a situação da área da bacia através da avaliação dos indicadores separadamente e a Tabela 13 revela uma posição geral.

Considerando as faixas de sustentabilidade ambiental descritas por Coelho (2008), demonstradas pela Tabela 14, verifica-se que pela pontuação total obtida de 60,50 a bacia do Rio Lençóis ocupa uma posição intermediária.

Tabela 14. Classificação geral da bacia do Rio Lençóis - SP.

\begin{tabular}{cc}
\hline Indicador & Faixas de Sustentabilidade \\
\hline Sustentável & $85-100$ \\
Potencialmente Sustentável & $70-84$ \\
Intermediário & $50-69$ \\
Potencialmente não Sustentável & $30-49$ \\
Não Sustentável & $0-29$ \\
\hline
\end{tabular}

\section{CONCLUSÕES}

Durante a elaboração deste estudo pode-se observar que a implantação de um indicador deve ser feita gradualmente, pois dificilmente pode-se contar com uma base de dados segura, tendo então que se iniciar um processo de mensuração mais sistemático para que se consiga alcançar os objetivos. Em casos mais complexos, esse processo pode levar um 
longo tempo até que as bases de dados assim como os procedimentos metodológicos estejam satisfatoriamente definidas e calibradas.

Os indicadores que nortearão as avaliações devem ser selecionados pelos seus usuários, de forma gradual, para que satisfaça às várias necessidades de um sistema de planejamento e gestão ambiental e de recursos hídricos. Para que isso ocorra este sistema de indicadores deve ser mensurável e atualizável periodicamente e ser sensível às mudanças que deve medir.

A utilização de um SIG permitiu a formação de uma base de dados segura e atualizável, permitindo aos municípios a ampliação de suas análises de acordo com suas necessidades.

Também é possível por essa metodologia a ampliação das análises com a ampliação dos indicadores, como por exemplo, um indicador que insira uma avaliação social e econômica das ações ambientais necessárias.

A área da bacia do Rio Lençóis apresentou índice de sustentabilidade ambiental 60,50, que representa uma posição intermediária entre o sustentável e o não sustentável.

De toda forma, com este estudo pode-se reafirmar a importância da geração de informações precisas e seguras que darão base para os municípios implementarem políticas públicas adequadas, pois é dentro dos limites do município que são definidas as ações que impactam diretamente nos recursos naturais. É preciso, portanto que se fortaleça e subsidie os municípios para conseguirem realizar os diagnósticos necessários para realização de uma gestão apoiada em uma base de informação segura e atualizável, proporcionando um planejamento eficiente.

\section{REFERÊNCIAS BIBLIOGRÁFICAS}

ARAUJO, Paulo Rogério de; PINESE, José Paulo P. Planejamento ambiental em microbacias hidrográficas: aplicação de uma matriz de impacto ambiental na microbacia hidrográfica do Ribeirão Lindóia, Zona Norte de Londrina-PR. Disponível em: $<$ http://www.fag.edu.br/professores/praraujo/EAIA/Planejamento $\% 20$ ambiental\%20em $\% 20 \mathrm{~m}$ icrobacias\%20hidrograficas.pdf >. Acesso em: 28 jul. 2012.

BARBOSA, Catia Fernandes et al. Sistema de gestão de recursos hídricos através de sistema de gestão ambiental (SGA) em áreas de proteção ambiental municipais (APA ou APAM). Disponível em: <www.cnrh.gov.br/sitio/index.php?option=com...task>. Acesso em: 26 ago. 2009.

CÂMARA, Gilberto; DAVIS, Clodoveu; MONTEIRO, Antonio Miguel Vieira (Org.). Introdução à ciência da geoinformação. São José Dos Campos: Inpe, 2001. 345 p. Disponível em: <http://www.dpi.inpe.br/gilberto/tutoriais/gis_ambiente/3opera.pdf >. Acesso em: 15 set. 2006.

CÂMARA, Gilberto; MEDEIROS, José Simeão. Modelagem de dados em geoprocessamento. 2001. Cap. 2, p. 35. Disponível em: <www.dpi.inpe.br/gilberto/tutoriais/gis_ambiente/2modelo.pdf>. Acesso em: 15 set. 2006. 
CASTRO, Leslie Ivana Serino. Diagnóstico ambiental na sub-bacia do Ribeirão Pouso Alegre com a utilização de um sistema de informação geográfica. 2008. 133 f. Dissertação Mestrado - Faculdade de Ciências Agronômicas, UNESP, Botucatu.

COELHO, Adoniran Martins. Proposta para um indicador global de avaliação de sustentabilidade ambiental de empreendimentos (IGSA). 2008. 182 f. Dissertação Mestre - Universidade Lusófona de Humanidades e Tecnologias, Lisboa. Disponível em: $<$ http://recil.grupolusofona.pt/bitstream/handle/10437/83/dissertacao_08_Final.pdf?sequence $=1>$. Acesso em: 19 jun. 2012 .

DAEE. Regionalização de vazões. Disponível em: <http://www.sigrh.sp.gov.br/cgibin/regnet.exe?lig=podfp >. Acesso em: 14 jun. 2012.

DISPÕE SOBRE OS PROCEDIMENTOS DE CONTROLE E DE VIGILÂNCIA DA QUALIDADE DA ÁGUA PARA CONSUMO HUMANO E SEU PADRÃO DE POTABILIDADE.. Portaria $n^{\circ}$ 2914, de 12 de dezembro de 2011. Portaria $\mathbf{N}^{\mathbf{o}} \mathbf{2 . 9 1 4}$, de 12 de Dezembro de 2011. Disponível em:

<http://bvsms.saude.gov.br/bvs/saudelegis/gm/2011/prt2914_12_12_2011.html>. Acesso em: 10 jan. 2012.

FEHIDRO. CBH Tietê - Jacaré. Relatório zero. São Paulo. Disponível em: <http://www.sigrh.sp.gov.br/cgibin/sigrh_home_colegiado.exe?COLEGIADO=FEHIDRO>. Acesso em: 08/2000.

LANNA, Antônio Eduardo. Gestão de recursos hídricos. Porto Alegre: Instituto de Pesquisas Hidráulicas, UFRGS, 2004.

LEPSCH, I. F.; BELLINAZZI Jr.; R., BERTOLINI, D.; ESPÍNDOLA, C. R. Manual para levantamento utilitário do meio físico e classificação de terras no sistema de capacidade de uso: $4^{a}$ aproximação. Campinas: Sociedade Brasileira de Ciência do Solo, 1991. 175 p.

LOPES, Eymar Silva Sampaio; FERREIRA, Hilcéa Santos. TUTORIAL 10 aulas: SPRING básico. Disponível em: <http://www.dpi.inpe.br/spring/>. Acesso em: 01 set. 2005.

MARTINS, Fabrina Bolzan; ROCHA, José Sales Mariano; ROBAINA, Adroaldo Dias; KURTZ, Moraes, Silvia Margareti de Juli; KURTZ, Fabio Charão; GARCIA, Sandra Maria; SANTOS, Alessandro Herbert Oliveira; DILL, Paulo Roberto Jaques; NOAL, Tatiana Nardon. Zoneamento ambiental da sub-bacia hidrográfica do Arroio Cadena, Santa Maria (Rs): (estudo de caso). Cerne, Lavras, p.315-322, jul. 2005.

PISSARRA, Teresa Cristina Tarlé; POLITANO, Walter. A bacia hidrográfica no contexto do uso do solo com floresta. In: FUNEP (Comp.). Manejo e recuperação florestal. Jaboticabal, 2003. p. 24-54.

PNUMA. Escritório Regional para a América Latina e o Caribe (Ed.). Metodologia para a elaboração de relatórios geo cidades: manual de aplicação. Mexico, 2001. Disponível em: <http://www.unep.org.br/admin/publicacoes/texto/Manual_para_elaboracao_do_GEO_Cidad es.pdf>. Acesso em: 01 jun. 2012. 
POMPERMAYER, Raquel de Souza. Aplicação de análise multicritério para gestão de recursos hídricos: simulação para as bacias dos rios Piracicaba, Capivari e Jundiaí. 2003. 150 f. Dissertação Mestrado - Faculdade de Engenharia Agrícola, Unicamp, Campinas, 2003. Disponível em: <http://www.ambiente.sp.gov.br/wpcontent/uploads/cea/RaquelPompermayer.pdf>. Acesso em: 23 jun. 2012.

PORTO, Marcos Maia; TEIXEIRA, Sergio Grein. Portos e meio ambiente. São Paulo: Ed. Aduaneira Ltda., 2002.

ROCHA, José Sales Mariano da. Manual de projetos ambientais. Santa Maria: Imprensa Universitária, UFSM, 1997.

SANTOS, Marco Aurélio. Técnicas para diagnóstico ambiental: sistemas de informações geográficas. In: MAGRINI, Alessanra; SANTOS, Marco Aurélio. Gestão ambiental de bacias hidrográficas. Rio de Janeiro: Coppe, UFRJ, 2001. p. 225-235.

SILVA, Christian Luis da; LIMA, José Edmilson de Souza (Org.). Políticas públicas e indicadores para o desenvolvimento sustentável. São Paulo: Saraiva, 2010.

TOLEDO, Silvia Rodrigues Bio de. Indicadores de capacidade de gestão urbana dos governos locais nas cidades médias no estado de São Paulo. 2005. 130 f. Dissertação Mestrado - Departamento de Geografia, Unesp, Rio Claro. 